\title{
Influence of reprocessing on fibre length distribution, tensile strength and impact strength of injection moulded cellulose fibre-reinforced polylactide (PLA) composites
}

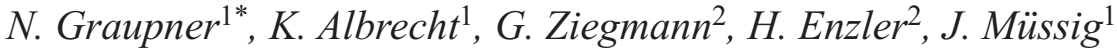 \\ ${ }^{1}$ HSB - City University of Applied Sciences, Dept. Biomimetics, The Biological Materials Group, Neustadtswall 30, \\ D-28199 Bremen, Germany \\ ${ }^{2}$ Institute for Polymer Materials and Plastics Processing, Clausthal University of Technology, Agricolastr. 6, \\ D-38678 Clausthal-Zellerfeld, Germany
}

Received 5 December 2015; accepted in revised form 29 February 2016

\begin{abstract}
The present study focuses on the reprocessing behaviour of recycled injection moulded polylactide (PLA) composites. The composites are reinforced with regenerated cellulose fibres (lyocell) of variable fineness and a fibre mass content of $30 \%$. They were reprocessed up to three times. The influence of reprocessing on the fibre length distribution and the resulting composite mechanical properties (tensile and impact strength) was analysed. While the first reprocessing cycle does not affect the mechanical characteristics of the neat PLA matrix, the strength of the composites decreases significantly due to a decreasing fibre aspect ratio. It was shown that fibres having a larger cross-sectional area display a lower aspect ratio than finer fibres, after reprocessing. This phenomenon leads to a larger decrease in tensile strength of composites reinforced with coarser fibres when compared to composites reinforced with finer fibres. A comparison of virgin composites and threefold reprocessed composites with a similar fibre length distribution resulted in a significantly higher tensile strength compared to the virgin sample. This result leads to the conclusion that not only the fibre length is drastically reduced by reprocessing but also that the fibres and the matrix were damaged.
\end{abstract}

Keywords: polymer composites, recycling, biocomposites, mechanical properties, processing technologies

\section{Introduction}

Due to increasing environmental awareness, the demand for recycled and reprocessed composites is growing, especially for man-made fibre-reinforced petrochemical-based plastics. Oliveux et al. [1] give an overview of the characteristics of recycled glass, carbon and aramid fibre-reinforced plastics and summarise the influences of different recycling techniques on the composite mechanical properties.

Many studies deal with the reprocessing of glass fibrereinforced composites. For the greater part virgin composites are reprocessed mechanically via shredding and injection moulding. While the Young's modulus is usually little affected, the tensile strength of reprocessed composites typically decreases with an increasing number of reprocessing steps due to fibre shortening. These effects were observed by Bourmaud and Baley [2,3] as well as by Dickson et al. [4] for glass fibre-reinforced polypropylene (PP) or by Bernasconi et al. [5] for glass fibre-reinforced polyamide (PA) 6.6 among others.

Recycling is becoming even more important for natural fibre-reinforced composites. 30000 tonnes of natural fibres were used 2012 in the European automotive industry, an increase from around 19000 tonnes of natural fibres towards 2005 [6]. Since 2015, the 
European automotive industry must recycle 95 mass $\%$ of an automobile [7]. Only $5 \%$ of the materials may be discarded. $10 \%$ may be incinerated and $85 \%$ must be recycled. Since the mass of natural fibre-reinforced composites in automotive applications has significantly increased in recent years, recycling is becoming increasingly important for this class of materials. Most natural fibre-reinforced composites are produced with thermoplastic polymers as a matrix. Some approaches exist for the mechanical reprocessing of composites and the further processing by injection moulding, e.g. for flax fibre-reinforced PP [4, 8], flax fibre-reinforced polylactide (PLA) [9], hemp fibre-reinforced PP [2, 3], sisal fibre-reinforced PP $[2,3]$, wood fibre-reinforced PP $[4,10]$, wood fibrereinforced high density polyethylene (HD-PE) [11] or alfa fibre-reinforced polyvinylchloride (PVC) [12]. A decrease in fibre length during reprocessing was found for all cited studies. An opposite trend was observed for the void fraction, which was observed to decrease during reprocessing, leading to a more homogeneous composite structure and a better wetting of the fibres within the matrix $[12,13]$.

The main problem which appears during reprocessing is the shortening of fibres, leading to a lower aspect ratio when single man-made fibres are considered. Since the most plant fibres are arranged in fibre bundles, it is possible that these fibre bundles are split into smaller fibre bundles or single fibres. It should be noted that different natural fibre bundles show different breakage during processing. Depending on their chemical composition, elementary fibre cells and mechanical strength, natural fibres present more or less extensive breaking and disaggregation during processing. Beaugrand and Berzin have shown that the aspect ratio of hemp fibres in a polycaprolactone (PCL) matrix increases when plasticised in water [14]. Le Moigne et al. [15] investigated the length and aspect ratio of flax, sisal and wheat straw extracted from their PP based composites after injection moulding. Flax was mainly broken into elementary fibres whereas sisal still showed fibre bundles and single fibres. In contrast to this, wheat straw showed bundles and particles of low aspect ratios. In the case where fibre bundles are opened to smaller bundles or single fibres the aspect ratio may increase during reprocessing, in contrast to single glass fibres which have a decreasing aspect ratio. The lower decreasing aspect ratio of flax fibres leads to a lower decrease of the composites' tensile strength after reprocessing when compared to glass fibre-reinforced composites [9]. Moreover the interface quality influences the fibre breakage. As shown for lyocell fibre-reinforced composites, the length of fibres extracted from injection moulded PP composites with a weaker fibre/matrix adhesion was higher when compared to fibres extracted from an injection moulded PLA composite [16]. Generally, the tensile strength decreases when the fibre length of short fibres is reduced. This is especially the case for changes in length of fibres with values around the critical fibre length, e.g. by (re)processing, as it has a large effect on the composites' tensile strength. A work by Fu and Lauke [17] has shown that an increase of the fibre length around and even above the critical fibre length, up to a value where the maximum tensile strength of a composite is achieved, has a significant influence on the composites' tensile strength. In particular, an increasing number of fibres with length values below the critical fibre length leads to a decrease of composite tensile strength values [18]. Hence, an investigation of processing and reprocessing of composites as a function of the fibre length is very important. No recent studies were found which address the reprocessing behaviour of composites reinforced with regenerated cellulose fibres. This study is an attempt to identify the influences on the composite mechanical properties as a function of the fibre fineness and the number of reprocessing cycles of lyocell fibre-reinforced PLA.

\section{Materials and methods}

\subsection{Fibres and matrix}

Composites were produced from lyocell staple fibres (type Tencel ${ }^{\mathbb{R}}$, Lenzing AG, Lenzing, AT) with a length $>38 \mathrm{~mm}$ and a fineness of $1.3,6.7$ and 15.0 dtex (equivalent diameter: 10.5, 24.7 and $35.7 \mu \mathrm{m}$ ). The polylactide (PLA) matrix was supplied in the form of staple fibres (type Ingeo SLN 2660 D; Eastern Textile Ltd., Taipei, TW) with a fineness of 6.7 dtex and a length of $64 \mathrm{~mm}$. Fibres were produced from NatureWorks $^{\mathrm{TM}} 6202$ D PLA with a density of $1.24 \mathrm{~g} / \mathrm{cm}^{3}$, a melting temperature of $160-170^{\circ} \mathrm{C}$ and a glass transition temperature of $60-65^{\circ} \mathrm{C}$. 


\subsection{Composite processing}

\subsubsection{Composite production}

Multilayer webs were manufactured with a laboratory carding machine with a working width of $200 \mathrm{~mm}$ (Shirley Developments Limited SDL, Stockport, UK, serial number 02895) as semi-finished products. Lyocell fibres and PLA fibres were mixed during the carding process at environmental conditions (approx. $25^{\circ} \mathrm{C}, 45 \%$ relative humidity). The initial mass of lyocell and PLA fibres was calculated on the basis of the dry mass for a lyocell fibre mass content of $30 \%$. As reference samples multilayer webs were produced from $100 \%$ PLA fibres. The multilayer webs were then dried for $2 \mathrm{~h}$ at $105^{\circ} \mathrm{C}$ in a forced air oven (Thermicon ${ }^{\circledR}$, Heraeus GmbH, Hanau, DE). Following this, composite boards were produced with a compression moulding technique between two Teflon sheets. Hot compression moulding was carried out at $180^{\circ} \mathrm{C}$ for 3 min (press type HP-S10, Joos, Pfalzengrafenweiler, DE). Afterwards, the boards were compression moulded in a cold press (type HPS60, Joos, Pfalzengrafenweiler, DE) at $25^{\circ} \mathrm{C}$ for $3 \mathrm{~min}$. The pressure was set to $5 \mathrm{MPa}$ for the PLA reference sample and to $12 \mathrm{MPa}$ for the composites. Composite boards were shredded to granules (shredder type EBA 2326C, Krug \& Priester GmbH \& Co. $\mathrm{KG}$, Balingen, $\mathrm{DE}$ ) and were dried in a forced air oven for $2 \mathrm{~h}$ at $105^{\circ} \mathrm{C}$ (type 2111520000200 , Windaus-Labortechnik GmbH \& Co. KG, Tullingen, DE). Injection moulding was carried out with an Arburg 320C Allrounder 600-250 machine (Arburg GmbH + Co KG, Loßburg, DE; Screw: ø30 mm, circumferential speed $20 \mathrm{~m} / \mathrm{min}$; nozzle diameter: $5 \mathrm{~mm}$ ) at a temperature profile of $170-172-175-177-180^{\circ} \mathrm{C}$. The injection moulding machine nozzle was heated to $180^{\circ} \mathrm{C}$ and the injection mould was cooled to $25^{\circ} \mathrm{C}$. The injection pressure, the backpressure and the hold pressure were set to 600,10 and 480 bar, respectively. The cooling time was $30 \mathrm{~s}$ in a standard test specimen tool (type $1 \mathrm{~A}$ according to DIN EN ISO 527$2[19])$.

\subsubsection{Reprocessing}

Injection moulded composites were shredded into granules $(G)$ with a cutting mill type S15/20L (No. K10300; H. Dreher GmbH \& Co. KG, DE) equipped with a sieve of rectangular holes $\left(8 \times 8 \mathrm{~mm}^{2}\right)$. Granules were pre-dried for $2 \mathrm{~h}$ at $105^{\circ} \mathrm{C}$ and then injec- tion moulded in the same manner as described above. Composites reinforced with lyocell 1.3, 6.7 and 15.0 dtex were reprocessed once (R1). As an example lyocell/PLA composites reinforced with medium fine lyocell 6.7 dtex fibres were additionally reprocessed two (R2) and three times (R3).

\subsection{Composite testing}

Prior to mechanical composite characterisation, test specimens were conditioned according to DIN EN ISO 291 [20] at $23^{\circ} \mathrm{C}$ and $50 \%$ relative humidity.

\subsubsection{Tensile strength}

At least 5 test specimens (type $1 \mathrm{~A}$, DIN EN ISO 527-2 [19]) were tested with a universal testing machine type Zwick Z 020 (Zwick/Roell, Ulm, DE) working with a load cell of $20 \mathrm{kN}$ and a Zwick/Roell pneumatic clamping system (clamping pressure: 12 bar). The gauge length was fixed to $100 \mathrm{~mm}$. A preload of $50 \mathrm{~N}$ was used and the test was performed with a speed of $2 \mathrm{~mm} / \mathrm{min}$.

\subsubsection{Impact strength}

The unnotched Charpy impact strength was determined with a pendulum impact testing machine (type 5101, Zwick, Ulm, DE) operating with a pendulum hammer of $2 \mathrm{~J}$ according to DIN EN ISO 179 [21]. In deviation from the standard, 5 test specimens instead of the usual 10 with the dimensions of $80 \times 10 \times$ $4 \mathrm{~mm}^{3}$ were investigated. The bearing distance was set to $40 \mathrm{~mm}$. The sample was hit on the flatwise impact direction.

\subsubsection{Differential scanning calorimetry (DSC)}

DSC of PLA composites was carried out with a DSC device type Q2000 V24.11 Build 124 (TA instruments, New Castle, USA) in a temperature range between 0 and $200^{\circ} \mathrm{C}$ (ramp $10^{\circ} \mathrm{C} / \mathrm{min}$ ) under a nitrogen flow of $50 \mathrm{~mL} / \mathrm{min}$. The first and second heating cycles were analysed.

\subsection{Fibre extraction}

For the determination of the fibre length distribution and the actual fibre mass content, fibres were extracted from granules and composites. For this purpose the composites were conditioned according to DIN EN ISO 139 [22]. Ca. $1 \mathrm{~g}$ of a composite from the parallel section of a tensile test specimen was weighed 
exactly in a Duran ${ }^{\circledR}$ filter crucible with a porosity of 3 and a volume of $30 \mathrm{~mL}$ (Carl Roth $\mathrm{GmbH} \&$ Co. $\mathrm{KG}$, Karlsruhe, DE) with a scale (type Kern ABT 120-5 DM, $d=0.00001 \mathrm{~g}$; Kern und Sohn GmbH, Balingen, DE). The crucibles were then boiled for 15 min in xylene (97\%, Carl Roth GmbH \& Co. KG, Karlsruhe, DE) and filtered with suction using a vacuum pump and a filter flask. The procedure was repeated up to five times until no precipitated polymer appears. Then the crucibles were dried for $0.5 \mathrm{~h}$ at $105^{\circ} \mathrm{C}$, conditioned and weighed a second time according to DIN EN ISO 139 [22]. The fibre mass content was calculated from the initial mass and the fibre mass after extraction. The extracted fibres were used for the measurement of the fibre length.

\subsection{Fibre testing}

Prior to the investigations, fibres were conditioned according to DIN EN ISO 139 [22] at $20^{\circ} \mathrm{C}$ and $65 \%$ relative humidity.

\subsubsection{Tensile test}

Tensile characteristics of raw lyocell fibres were determined with a Fafegraph M testing machine (Textechno, Mönchengladbach, DE) working with a pneumatic clamping system (PVC/PMMA clamps). More than 70 fibres were investigated with a load cell of $100 \mathrm{cN}$ at a gauge length of $3.2 \mathrm{~mm}$ and a testing speed of $2 \mathrm{~mm} / \mathrm{min}$.

\subsubsection{Fibre length}

The measurement of the fibre length distribution was performed for more than 500 fibres in each sample with the image analysis software Fibreshape 5.1.1 (IST AG, Vilters, $\mathrm{CH}$ ). Fibres were prepared on a slide frame $\left(40 \times 40 \mathrm{~mm}^{2}\right.$, glass thickness $2 \mathrm{~mm}$, company Gepe, Zug, CH) and scanned (4000 dpi resolution for lyocell 1.3, 2400 dpi resolution for lyocell $6.7 \mathrm{dtex}$ and $2000 \mathrm{dpi}$ resolution for lyocell $15.0 \mathrm{dtex}$ ). Intersecting fibres were not considered for the evaluation. An image used for the measurement of the fibre length is shown as an example in Figure 1. Red ellipses indicate intersecting fibres. A high number of intersecting fibres may lead to a reduction of the length value, since the probability for fibre intersections increase with increasing fibre length. Therefore, care should be taken during fibre preparation to reduce the number of fibre intersections.

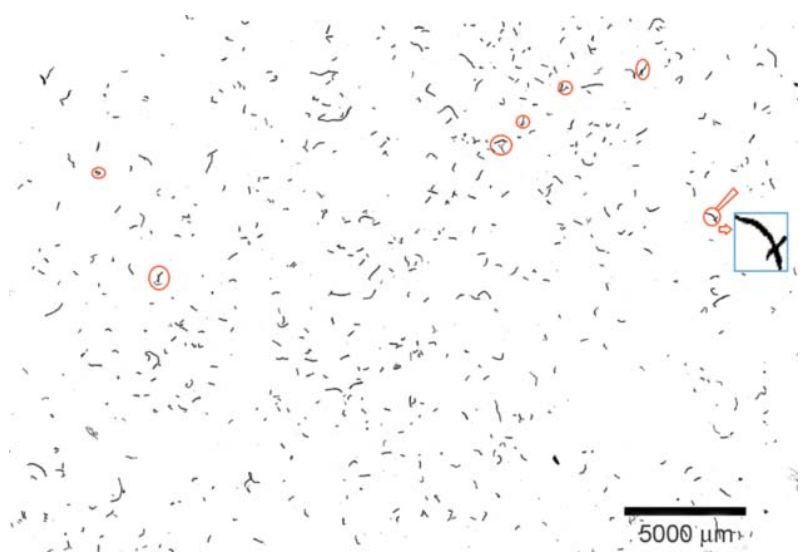

Figure 1. Scan of extracted fibres from a PLA composite reinforced with lyocell 15.0 dtex (R1). Red ellipses show intersecting fibres.

A comparison of the measured fibre length $L$ with the critical fibre length $L_{\mathrm{c}}$ (fibre length which is necessary to reach a reinforcing effect in a matrix) is of particular importance. When the interfacial shear strength $\tau$ between fibre and matrix is known, $L_{\mathrm{c}}$ can be calculated according to Equation (1) with the tensile strength $\sigma_{\mathrm{f}}$ of the fibre and the equivalent fibre diameter $d_{\mathrm{f}} . L_{\mathrm{c}}$ was determined for lyocell in PLA with a pull-out test in a previous study [23]:

$L_{\mathrm{c}}=\frac{\sigma_{\mathrm{f}} \cdot d_{\mathrm{f}}}{2 \cdot \tau}$

\subsubsection{Scanning electron microscopy (SEM)}

Fibre surfaces and fracture surfaces of composites were investigated with a SEM type JSM 6510 (Jeol, Eching, DE) operating with emission electrons at a current of $10 \mathrm{kV}$. Prior to SEM investigation the samples were sputtered with gold for $90 \mathrm{~s}$ under a current of $56 \mathrm{~mA}$ with a Bal-Tec sputter coater type SCD 005 (Bal-Tec, Liechtenstein).

\subsection{Statistics}

The statistical evaluation of the results was carried out with the open source R software (http://www.rproject.org/) with a Shapiro-Wilk test [24] regarding a normal distribution of $n<5000$. To discover if there were significant differences between the data of variable samples, for normally distributed data with homogenous variances the Tukey-test [25] was used and for data which were not distributed normally the Wilcoxon test [26] was chosen. All tests were performed with a level of significance $a=0.05$. Results are shown as Box-Whisker plots or histograms 


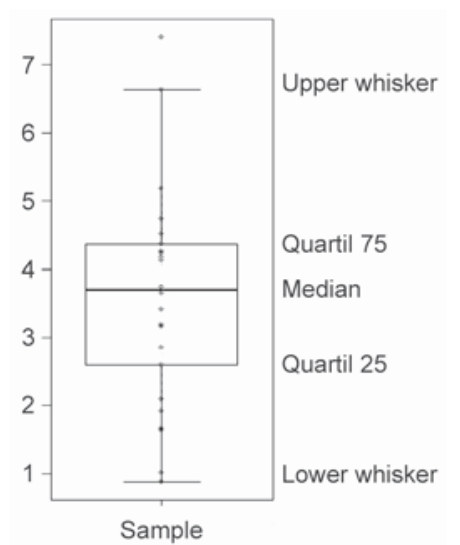

Figure 2. Box-Whisker plot with median value and the second and third quartile

[27, 28]. A typical Box-Whisker plot, showing the median, the $2^{\text {nd }}$ (Quartil 25) and $3^{\text {rd }}$ quartile (Quartil 75 ) and 1.5 times the interquartile length (Whiskers) is shown in Figure 2. Since many results are not distributed normally, values reported in the text are given as median value \pm mean arithmetic deviation. Significant differences within one series of experiments are marked with different letters above the plots and an asterisk shows results which are not distributed normally.

\section{Results and discussion}

\subsection{Fibre mass content}

In order to compare the properties of the composites with each other, the fibre mass fraction of the composites should not deviate significantly from each other. Table 1 shows the fibre mass content of virgin composites, reprocessed granules $(\mathrm{G})$ and reprocessed

Table 1. Fibre mass content of virgin composites as well as reprocessed granules and composites determined by fibre extraction (G: granules, R1: first reprocessing step, R2: second reprocessing step, R3: third reprocessing step)

\begin{tabular}{|l|c|c|}
\hline \multirow{2}{*}{ Composite } & \multicolumn{2}{c|}{ Fibre mass content } \\
& [\%] \\
\cline { 2 - 3 } & Actual value & Nominal value \\
\hline $30 \%$ lyocell 1.3 dtex/PLA & 28 & 30 \\
\hline $30 \%$ lyocell 1.3 dtex/PLA, R1 & 27 & 30 \\
\hline $30 \%$ lyocell 6.7 dtex/PLA & 28 & 30 \\
\hline $30 \%$ lyocell 6.7 dtex/PLA, G, R1 & 29 & 30 \\
\hline $30 \%$ lyocell 6.7 dtex/PLA, R1 & 29 & 30 \\
\hline $30 \%$ lyocell 6.7 dtex/PLA, G, R2 & 29 & 30 \\
\hline $30 \%$ lyocell 6.7 dtex/PLA, R2 & 29 & 30 \\
\hline $30 \%$ lyocell 6.7 dtex/PLA, G, R3 & 29 & 30 \\
\hline $30 \%$ lyocell 6.7 dtex/PLA, R3 & 30 & 30 \\
\hline $30 \%$ lyocell 15.0 dtex/PLA & 28 & 30 \\
\hline $30 \%$ lyocell 15.0 dtex/PLA, R1 & 28 & 30 \\
\hline
\end{tabular}

composites (R1, R2, R3) resulting from the fibre extraction. Reprocessed granules were produced from tensile test specimens via shredding and were then used for the production of reprocessed composites via injection moulding. The results show that the maximum deviation of the fibre mass content compared to the nominal fibre mass content (30\%) is 3\% for lyocell $1.3 \mathrm{dtex} / \mathrm{PLA}, \mathrm{R} 1$. The maximum deviation of composites within one series of experiments is $2 \%$. The extraction method itself provides an accuracy of $\pm 1 \%$. Therefore, the measured deviations are negligible and the results of the composites are comparable.

\subsection{Fibre tensile strength}

As shown in Figure 3, the results of the tensile strength values of virgin lyocell fibres are not distributed normally and decrease significantly with increasing fibre cross-section. The median fibre strength decreases from $511( \pm 71) \mathrm{MPa}$ for lyocell 1.3 dtex to $448( \pm 52) \mathrm{MPa}$ for lyocell 6.7 dtex and $348( \pm 64) \mathrm{MPa}$ for lyocell 15.0 dtex, respectively. This behaviour could be explained by a higher probability for defects in the cross-sectional area due to the higher fibre volume. This trend was confirmed by Moon et al. [29] and Wilson [30] for glass and ceramic fibres as well. The lower fibre strength and specific fibre surface of coarser fibres compared to fine fibres should be considered in the evaluation of the composite mechanical characteristics.

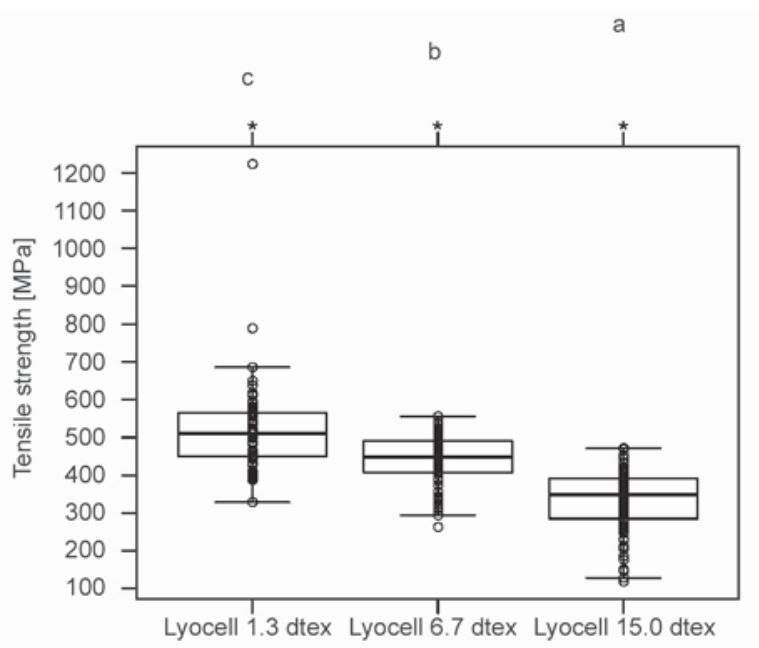

Figure 3. Tensile strength of lyocell fibres of variable fineness shown as Box-Whisker plots (significant differences are marked with different letters; an asterisk shows results which are not distributed normally) 


\subsection{Influence of fibre fineness and reprocessing on the composite mechanical properties}

\subsubsection{Tensile and impact strength of composites}

The tensile strength was investigated for composites reinforced with lyocell of variable fineness as well as for the neat PLA reference sample. PLA matrix and composites were reprocessed once. The tensile strength results are shown in Figure 4. It is shown that the tensile strength of neat PLA was reduced only slightly from $60( \pm 0.1)$ to $58( \pm 0.2) \mathrm{MPa}$ due to reprocessing. Courgneau et al. [31] reported that the molecular weight of neat PLA decreases due to compounding which has a strong impact on the degradation. It was shown that the combination of water granulation after compounding and a following drying leads to a clear reduction of the molecular mass of PLA. Since our granules were prepared via compression moulding and shredding this aspect can be negated. Moreover Courgneau et al. [31] stated that injection moulding itself does not have a significant impact on the degradation of neat PLA. Lekube [32] confirmed the low degradation of neat PLA due to injection moulding and showed only a slightly lower tensile strength of neat PLA reprocessed in five cycles compared to virgin PLA.

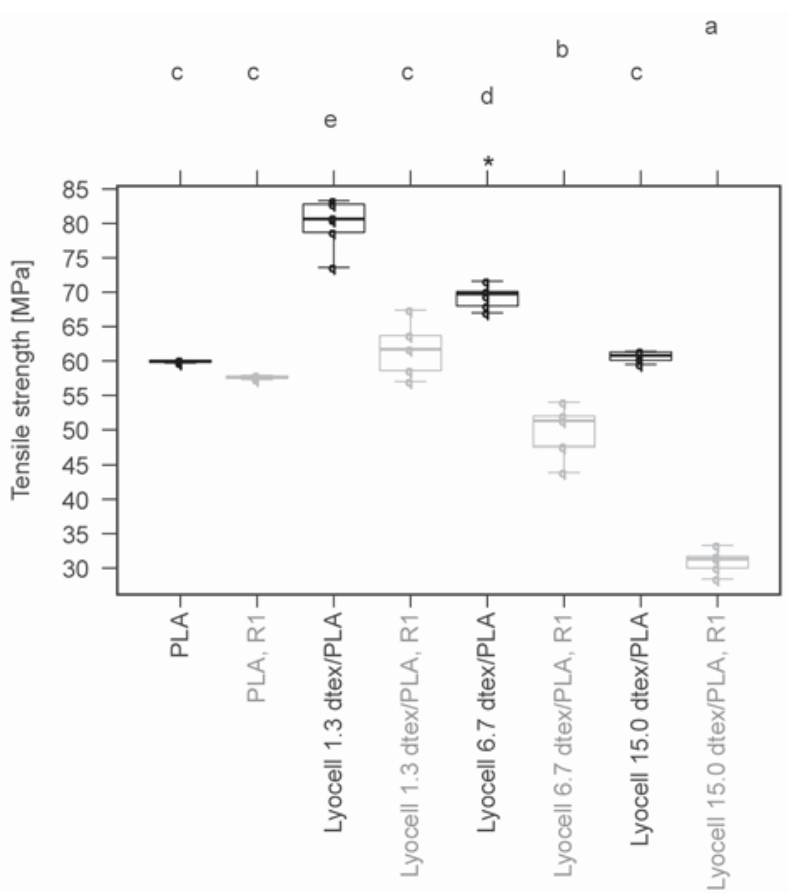

Figure 4. Tensile strength of PLA matrix and lyocell/PLA composites in virgin state and reprocessed (R1) shown as Box-Whisker plots (significant differences are marked with different letters; an asterisk shows results which are not distributed normally)
When considering the virgin composites, a significant decrease of tensile strength with increasing fibre cross-section can be seen. This effect is caused by the decreasing tensile strength of fibres with an increasing cross-sectional area as well as a decreasing specific fibre surface for fibre/matrix interaction as described by Moon et al. [29] for glass fibres embedded in epoxy and HDPE. Significantly the highest reinforcing effect was determined for composites reinforced with the finest fibre (1.3 dtex) resulting in a tensile strength of $81( \pm 2.5) \mathrm{MPa}$. Compared to the neat matrix this is an increase by factor 1.34. Moreover, a significant enhancement effect was measured for lyocell $6.7 \mathrm{dtex} / \mathrm{PLA}$ with a value of $70( \pm 1.2) \mathrm{MPa}$ which is an improvement by a factor of 1.16 . For the composite reinforced with the coarse lyocell $15.0 \mathrm{dtex}$ fibres with a tensile strength of $61( \pm 0.7) \mathrm{MPa}$ no reinforcement effect was detected (factor 1.01).

Reprocessed composites show significantly lower values when compared to virgin samples. As presented in Figure 4, the tensile strength of virgin composites decreases drastically with an increasing fibre cross-section. Compared to virgin composites no significant reinforcement effect was achieved for lyocell $1.3 \mathrm{dtex} / \mathrm{PLA}$ with a tensile strength of $62( \pm 3.1) \mathrm{MPa}$ (factor of 1.07). For lyocell $6.7 \mathrm{dtex} /$ PLA and lyocell 15.0 dtex/PLA decreases by factors of 0.89 and 0.54 with tensile strength values of $51( \pm 3.2)$ and $31( \pm 1.4) \mathrm{MPa}$ were measured, respectively.

As reported by Courgneau et al. [31] an additional aspect besides process induced fibre shortening, resulting in reduced tensile strength data of composites could be the degradation of the PLA matrix due to the higher moisture content of cellulose fibres compared to PLA. Moisture leads to a reduction of the molecular weight of PLA due to hydrolysis and a decrease in length of the polymer chains. This effect might be increased by reprocessing, since the granules in the intermediate processing step can absorb moisture, which may result in further hydrolysis of the polymer chains of the PLA matrix during the following injection moulding step.

The crack initiation measured with the unnotched Charpy impact test (Figure 5) shows similar trends as described for the tensile strength. The impact strength of virgin neat PLA decreases only slightly from $11( \pm 1.5)$ to $10( \pm 1.0) \mathrm{kJ} / \mathrm{m}^{2}$ for the reprocessed 


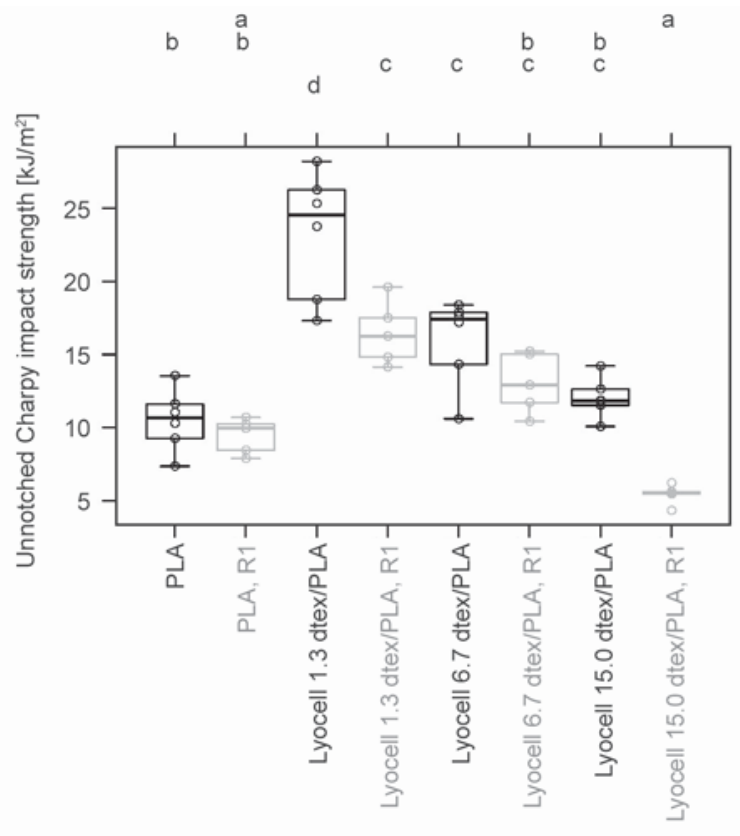

Figure 5. Unnotched Charpy impact strength of PLA and lyocell/PLA composites in virgin state and reprocessed (R1) shown as Box-Whisker plots (significant differences are marked with different letters; all results are distributed normally)

PLA. For both virgin and reprocessed composites, a clear influence by fibre fineness was detected with decreasing impact strength values for composites reinforced with coarser fibres. But in comparison to the tensile strength, the reinforcing effect of the fibres is higher. For virgin lyocell $1.3 \mathrm{dtex} / \mathrm{PLA}$ the impact strength increased up to a value of $25( \pm 3.5) \mathrm{kJ} / \mathrm{m}^{2}$ which is an improvement by a factor of 2.30. For lyocell 6.7 and 15.0 dtex values of $17( \pm 2.4)$ and $12( \pm 0.9) \mathrm{kJ} / \mathrm{m}^{2}$ were achieved (improvement factors of 1.63 and 1.11, respectively). In contrast to the tensile strength data, reprocessed composites reinforced with lyocell 1.3 dtex and lyocell 6.7 dtex display significantly higher impact values compared to the neat matrix. Values of $16( \pm 1.7)$ and $13( \pm 1.6) \mathrm{kJ} / \mathrm{m}^{2}$ were achieved corresponding to improvement factors of 1.63 and 1.30. A decrease of impact strength by a factor of 0.55 was determined for lyocell $15.0 \mathrm{dtex} / \mathrm{PLA}\left(6( \pm 0.4) \mathrm{kJ} / \mathrm{m}^{2}\right)$. The reasons for the lower values of reprocessed composites compared to virgin samples are the same as those described for the tensile strength.

Despite a multiple higher tensile strength of the fibres compared to the PLA matrix a reinforcement effect was not achieved for the tensile strength of lyocell 15.0 dtex/PLA. A previous study has shown a
1.5 times higher tensile strength with a value of $76 \mathrm{MPa}$ for lyocell $15.0 \mathrm{dtex} / \mathrm{PLA}$ when compared to pure PLA [33]. In contrast to the present study, the composites were processed with much longer fibres (fibre length $60 \mathrm{~mm}$ ) via compression moulding leading to a higher reinforcing effect. Therefore, it is important to evaluate the fibre length distribution and the influence of the fibre length on the mechanical composite properties.

\subsubsection{Fibre length distribution}

The first reprocessing step (R1) has shown to significantly influence the mechanical characteristics of the composites. From this standpoint, the hypothesis, that fibres are strongly damaged due to the recycling process is verified. It is known that processing via extrusion and injection moulding leads to a clear fibre shortening as shown by Joffre et al. [13] for wood/PLA composites or Erdmann and Ganster [34] for Cordenka fibre-reinforced PLA composites. Hence, any further reprocessing can lead to additional fibre shortening.

In this study, the fibre length distribution was investigated for fibres which were extracted from virgin and reprocessed composites. Figure 6 shows the percentages of fibre length distributions as histograms. A higher frequency of longer fibres was observed for both, virgin and reprocessed composites, with increasing fibre cross-section. As a result, $67 \%$ of lyocell 1.3 dtex fibres, extracted from virgin composites, have a fibre length of $>300 \mu \mathrm{m}$ while lyocell 6.7 dtex and lyocell 15.0 dtex show values of 76 and $73 \%$, respectively. However, reprocessed composites contain fibres of a length $>300 \mu \mathrm{m}$ only to 36,48 and $62 \%$ of lyocell 1.3 dtex, lyocell 6.7 dtex and lyocell 15.0 dtex respectively.

The critical fibre length of lyocell fibres of variable fineness was determined and calculated in previous studies [33, 35] and is presented as rhombuses in Figure 7a. Since the results of the fibre length measurements are not distributed normally, the median values are utilised. As reported by Le Moigne et al. [15] fibre length can be strongly influenced and biased by extreme values. It is obvious that the median fibre length of virgin lyocell $1.3 \mathrm{dtex} / \mathrm{PLA}$ with a value of $467 \mu \mathrm{m}$ is clearly higher than the critical fibre length $L_{\mathrm{c}}(220 \mu \mathrm{m}$ [35]), while the fibre length of the reprocessed composite is on the level with the $L_{\mathrm{c}}$ 

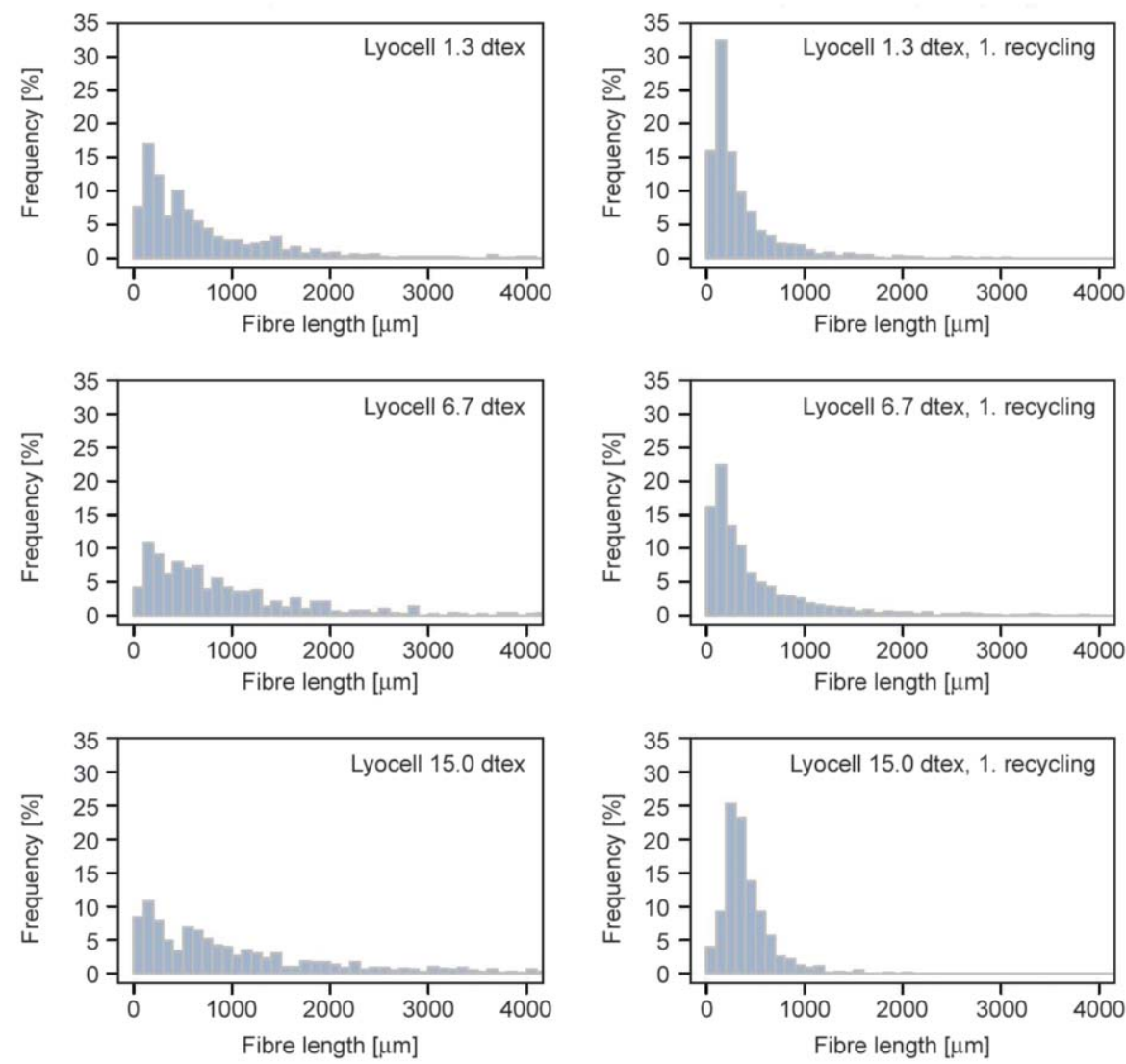

Figure 6. Histograms of fibre length distribution of fibres extracted from virgin and reprocessed (R1) PLA composites reinforced with lyocell fibres of various fibre fineness. Results are pooled in $200 \mu \mathrm{m}$ steps.
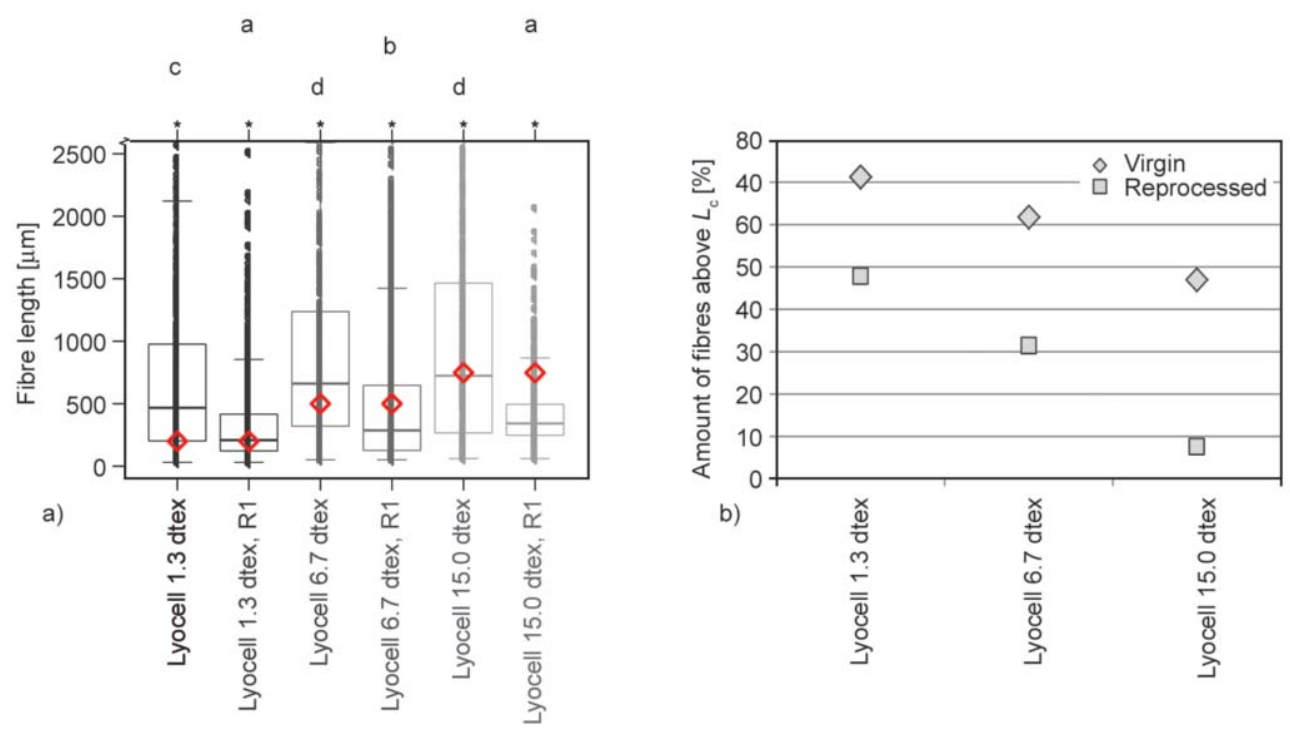

Figure 7. a) Fibre length of fibres with different fineness, extracted from virgin and reprocessed (R1) lyocell/PLA composites. Rhombuses show the critical fibre length of the different fine fibres (significant differences are marked with different letters; an asterisk shows results which are not distributed normally). b) Percental amount of fibres extracted from virgin and reprocessed composites above the critical fibre length $L_{\mathrm{c}}$.

value of $209 \mu \mathrm{m} .71 \%$ of the fibres used in the virgin lyocell $1.3 \mathrm{dtex} / \mathrm{PLA}$ composite display length values above $L_{\mathrm{c}}$ (view Figure $7 \mathrm{~b}$ ); the reprocessed composite contains $48 \%$ fibres longer than $L_{\mathrm{c}}$. For virgin ly- ocell $6.7 \mathrm{dtex} / \mathrm{PLA}$ the median fibre length of $661 \mu \mathrm{m}$ is slightly higher than $L_{\mathrm{c}}(500 \mu \mathrm{m}$ [35]) and represents $62 \%$ of fibres having length values higher than $L_{\mathrm{c}}$. The median fibre length of the reprocessed com- 
posite is with $287 \mu \mathrm{m}$ below $L_{c}$; in which only $31 \%$ of the fibres display a fibre length above $L_{\mathrm{c}}$. The virgin lyocell 15.0 dtex/PLA composite displays fibres with a median fibre length of $724 \mu \mathrm{m}$ which are on the level with the $L_{\mathrm{c}}(748 \mu \mathrm{m}$ [35]) and a total amount of $47 \%$ of fibres being longer than $L_{\mathrm{c}}$. The corresponding reprocessed composite shows the highest deviation between the median fibre length of $342 \mu \mathrm{m}$ and $L_{\mathrm{c}}$, with only $8 \%$ of fibres longer than $L_{\mathrm{c}}$.

These findings are in close alignment with the tensile strength results of the composites (compare Figure 4) and show tensile strength as a function of fibre length. The higher the fibre length compared to $L_{\mathrm{c}}$, the higher the tensile strength of the composite. Composites with a median fibre length close to the critical fibre length do not display a reinforcement effect and composites with a fibre length below the critical fibre length resulted in lower tensile strength values compared to the PLA matrix. It is known that even a slight increase in fibre length when around $L_{\mathrm{c}}$, leads to a considerably higher reinforcing effect as shown for the lyocell 6.7 dtex/PLA composite. This trend is confirmed by the work of $\mathrm{Fu}$ and Lauke [17] who reported considerable impacts by small changes of the fibre length made around $L_{\mathrm{c}}$ on the tensile strength of glass fibre-reinforced plastics.

The lower tensile strength of composites reinforced with coarser fibres is therefore based on one hand on lower fibre strength and on the other hand on the fibre length, especially the lower aspect ratio. As already discussed the coarse fibre breakages are lower during injection moulding and reprocessing compared to finer fibres (Figure 7). However, finer fibres display a lower equivalent diameter resulting in a higher aspect ratio despite the lower median fibre length (view Figure 8).

The critical aspect ratio which is necessary for a reinforcement effect was determined to be 21 in a previous study for lyocell $[33,35]$. The critical aspect ratio is calculated from the critical fibre length of lyocell divided by the fibre diameter. In the case of lyocell $15.0 \mathrm{dtex}$ the critical fibre length of $748 \mu \mathrm{m}$ is divided by the equivalent diameter of $35.7 \mu \mathrm{m}[33,35]$. Despite of the higher fibre length of the coarser fibres Figure 8a shows a decrease in the fibre aspect ratio with an increasing fibre cross-section. This effect is based on the higher equivalent fibre diameter of coarser fibres when compared to finer fibres
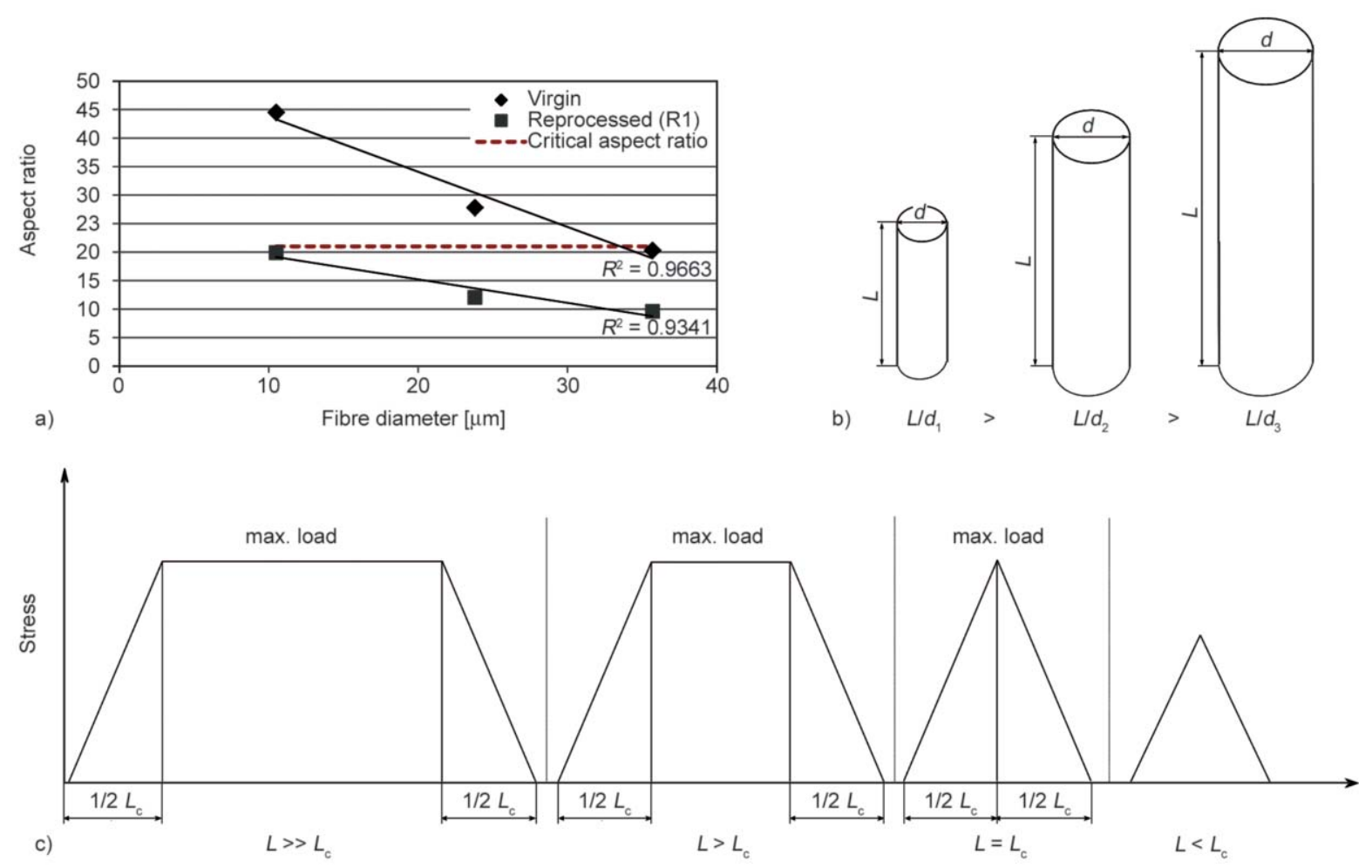

Figure 8. Aspect ratio of fibres extracted from virgin and reprocessed composites as a function of the equivalent fibre diameter (a); influence of fibre diameter on the aspect ratio (b) and maximum loaded fibre surface area (cylindrical fibre surface) as a function of the fibre length (c). 
(compare Figure 8b). E.g., the coarser the fibre the higher $L_{\mathrm{c}}$. Moreover, it is known that the debonding between a fibre and a matrix under mechanical loading usually starts at the fibre end [36, 37]. In composites with the same fibre mass shorter fibres mean a higher number of fibre ends where debonding can start. Fibres with a length equivalent to $L_{\mathrm{c}}$ may lead to a reinforcing effect, however, they cannot provide their full reinforcing potential. The fibres can be fully loaded, but only in a small area in the center (Figure 8c). Fibres with a length $>L_{\mathrm{c}}$ have a significantly higher surface area in which the fibre can be fully loaded, resulting in a higher tensile strength of the composite. The shorter the fibre, the easier it is to pull out from the matrix.

The median aspect ratio of fibres in virgin composites decreased from 45 for lyocell 1.3 dtex/PLA, to 28 for lyocell $6.7 \mathrm{dtex} / \mathrm{PLA}$ and 20 for lyocell $15.0 \mathrm{dtex}$. Fine ( $1.3 \mathrm{dtex})$ and medium fine $(6.7 \mathrm{dtex})$ fibres used in virgin composites display a clearly higher aspect ratio when compared to the critical aspect ratio. The aspect ratio of the coarsest fibre is equal to the critical aspect ratio.

Reprocessed fibres show an aspect ratio comparable to the critical aspect ratio in the case of the finest fibres with a value of 20 , while the medium fine and the coarse fibres display an aspect ratio below the critical aspect ratio with values of 12 and 10, respectively. It can be concluded that the fibre length, and especially the aspect ratio, have a significant impact on the decreasing tensile strength after reprocessing since the mechanical characteristics of PLA were only slightly reduced after one reprocessing step (view Figure 4). As already discussed the tensile strength of neat PLA is only slightly affected by reprocessing. Besides the decreasing fibre length and possible fibre damage due to reprocessing the residual moisture content may affect the molecular weight of PLA and the mechanical characteristics of the whole composite structure. As shown by Courgneau et al. [31] the residual moisture content of PLA composites reinforced with 10 mass $\%$ 'highly pure' cellulose fibres is nearly three times higher (640 ppm) than that of neat PLA (260 ppm). This effect leads to a reduction of the molecular weight and a shortening of the polymer chains of the PLA matrix which is highly sensitive towards moisture. NatureWorks ${ }^{\mathrm{TM}}$ recommends keeping the moisture content of 6202 D PLA matrix lower than $50 \mathrm{ppm}$ to prevent viscosity degradation and potential loss of properties of the PLA. Reinforcement with cellulose fibres leads to a higher degradation of the PLA matrix. It is assumed that a higher fibre mass fraction of $30 \%$ results in a higher moisture content. Moreover the increasing viscosity of the polymer melt due to an increasing cellulose fibre mass fraction may lead to a higher degradation of polymer chains due to higher thermal degradation. Hence, the degradation after one recycling step seems to be mainly influenced by fibre shortening while fibre damage, moisture resulting in a reduction of the length of the polymer chains, and thermal degradation additional affect the degradation of the composite.

\subsection{Influence of reprocessing cyles $(\mathrm{R} 1, \mathrm{R} 2$ and R3) on the mechanical composite characteristics}

\subsubsection{Fibre length}

To investigate the influence of the reprocessing cycle, three reprocessing steps were carried out exemplary for composites reinforced with the medium fine fibre (lyocell 6.7 dtex). Virgin composites, reprocessed granules and reprocessed composites were investigated for their fibre length distribution.

Figure 9 shows that there is a trend of an increasing number of shorter fibres as the number of reprocessing cycles increases. Due to the shredding process of the virgin lyocell $6.7 \mathrm{dtex} /$ PLA composites, the fibre length was shortened during reprocessing in the granules $(G, R 1)$. While the virgin composite contains $62 \%$ fibres $>L_{\mathrm{c}}$, the reprocessed granules only contain $40 \%$ fibres $>L_{\mathrm{c}}\left(L_{\mathrm{c}}=500 \mu \mathrm{m}\right)$. The following injection moulding process (R1) leads to a further fibre shortening and to only $31 \%$ of fibres with a length above $L_{\mathrm{c}}$. As it appears on the graph (Figure 9), shredding of reprocessed lyocell 6.7 dtex/PLA (R1) into granules $(G, R 2)$ resulted in a higher number of fibres with a length longer than $L_{\mathrm{c}}(37 \%)$. It is assumed that very short fibres were lost during sample preparation for fibre length measurements. Otherwise, the short fibre fraction would not be represented after the following reprocessing step (R2). The second reprocessing (R2) led to a lower amount of fibres $>L_{\mathrm{c}}(25 \%)$ in lyocell 6.7 dtex/PLA (R2) as well as in lyocell 6.7 dtex/PLA granules (G, R3) with $24 \%$ of fibres > $L_{\mathrm{c}}$. Finally, after the third reprocessing step (R3) only $22 \%$ of fibres have a length $>L_{\mathrm{c}}$. 

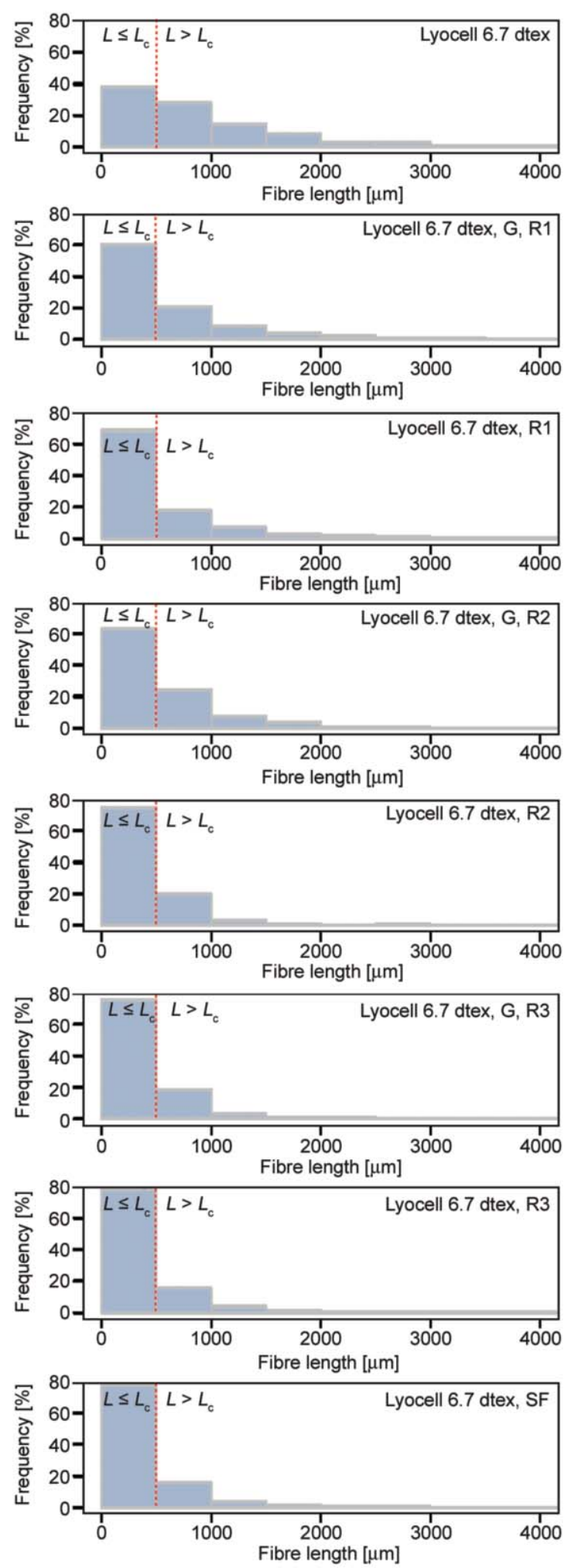

Figure 9. Histograms of the fibre length distribution of lyocell fibres with a fineness of 6.7 dtex extracted from PLA composites in virgin state, from reprocessed granules (G) and composites reprocessed in one (R1), two (R2) and three (R3) cycles, compared to short fibres (SF) extracted from virgin SF-reinforced composites. Results are pooled in $500 \mu \mathrm{m}$ steps. Bars below $500 \mu \mathrm{m}$ indicate fibres with a fibre length below the critical fibre length $L_{\mathrm{c}}$.
To evaluate whether the fibre length distribution has an influence on the composites and/or the fibre strength is affected by the reprocessing, additional experiments with virgin composites reinforced with short fibres (SF) were carried out (SF were produced from lyocell 6.7 dtex staple fibres with a cutting mill type SM100 (Retsch, Haan, DE) with a sieve size of $6 \mathrm{~mm})$.

The fibre length distribution of SF-reinforced composites as well as the median fibre length of $275 \mu \mathrm{m}$ is comparable to that of $\mathrm{R} 3$ reprocessed composites with a fibre length of $265 \mu \mathrm{m}$ (view Figure 9). Both composites contain $22 \%$ fibres of a length above $L_{\mathrm{c}}$ $(500 \mu \mathrm{m})$.

In Figure 10 the value of $L_{\mathrm{c}}$ of lyocell $6.7 \mathrm{dtex}$ $(500 \mu \mathrm{m})$ is added as rhombuses to the Box-Whisker plots of the fibre length distribution. It can be seen that the median fibre length in virgin lyocell $6.7 \mathrm{dtex} /$ PLA $(661 \mu \mathrm{m})$ is higher than $L_{\mathrm{c}}$, while reprocessing leads to lower values. The third reprocessing step resulted in a decrease in the median fibre length to a value of $265 \mu \mathrm{m}$. The results are summarised in Table 2. Additionally the weighted mean value and the polydispersity of the fibre length distributions were evaluated according to ISO 22315 [38]. The mean values, as well as the weighted mean values are

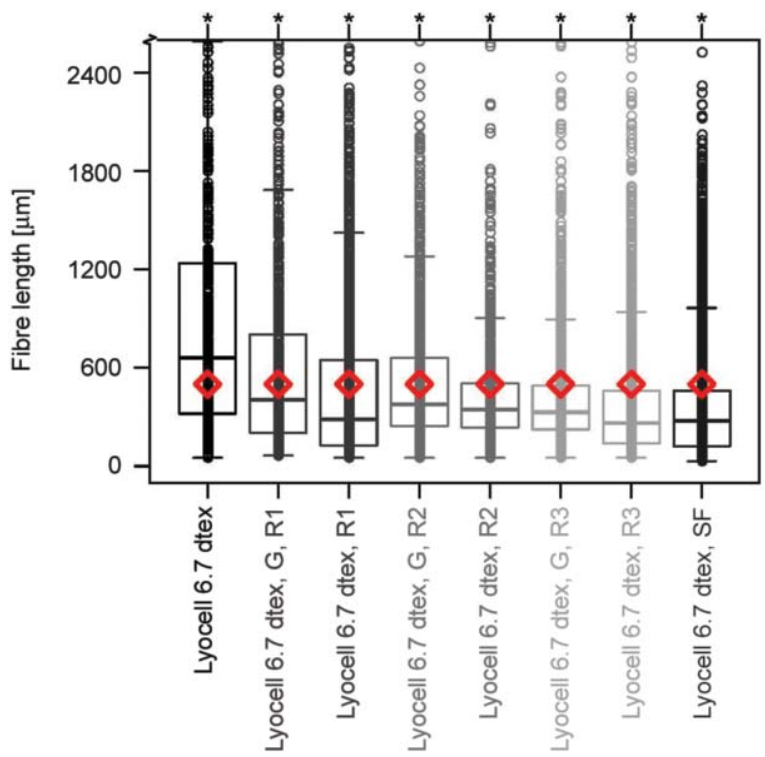

Figure 10. Fibre length of lyocell fibres with a fineness of 6.7 dtex extracted from PLA composites in virgin state, reprocessed granules $(\mathrm{G})$ and composites reprocessed one (R1), two (R2) and three times (R3) compared to short fibres (SF) extracted from virgin (SF)-reinforced composites. The critical fibre length of lyocell $6.7 \mathrm{dtex}(500 \mu \mathrm{m})$ is shown as rhombuses 
Table 2. Median fibre length, median aspect ratio and mean fibre length as well as weighted mean fibre length and polydispersity determined according to ISO 22314 [38] of lyocell 6.7 dtex fibres extracted from virgin and reprocessed composites

\begin{tabular}{|l|c|c|c|c|c|c|}
\hline \multicolumn{1}{|c|}{ Sample } & $\begin{array}{c}\text { Median } \\
{[\boldsymbol{\mu \mathbf { m } ]}}\end{array}$ & $\begin{array}{c}\text { Median aspect } \\
\text { ratio }\end{array}$ & $\begin{array}{c}\text { Mean } \\
{[\boldsymbol{\mu \mathbf { m } ]}}\end{array}$ & $\begin{array}{c}\text { Weighted mean } \\
{[\boldsymbol{\mu \mathbf { m } ]}}\end{array}$ & $\begin{array}{c}\text { Polydis- } \\
\text { persity }\end{array}$ & N \\
\hline 30\% lyocell 6.7 dtex, virgin & 661 & 27.8 & 983 & 2051 & 1.9 & 526 \\
\hline 30\% lyocell 6.7 dtex, R1 & 287 & 12.1 & 519 & 1337 & 2.3 & 2009 \\
\hline 30\% lyocell 6.7 dtex, R2 & 347 & 14.6 & 456 & 915 & 1.5 & 981 \\
\hline 30\% lyocell 6.7 dtex, R3 & 265 & 11.1 & 392 & 873 & 1.7 & 2689 \\
\hline 30\% lyocell 6.7 dtex, SF & 275 & 11.6 & 345 & 623 & 1.7 & 7295 \\
\hline
\end{tabular}

shown to decrease with an increasing number of reprocessing cycles (Table 2). Compared to the median value, the weigthed mean of virgin SF-reinforced composites is clearly lower compared to the threetime reprocessed composite (R3). The polydispersity, which is a measure of the heterogeneity of sizes of fibre lengths within the distribution, shows the same value of 1.7.

\subsubsection{Tensile strength}

As described for composites reinforced with fibres of variable fineness, the tensile strength of one, two and three-times reprocessed lyocell $6.7 \mathrm{dtex} / \mathrm{PLA}$ composites is in alignment with the findings of the fibre length distribution. The influence of reprocessing on the composites' tensile strength is shown in Figure 11 for virgin and reprocessed composites. Ad-

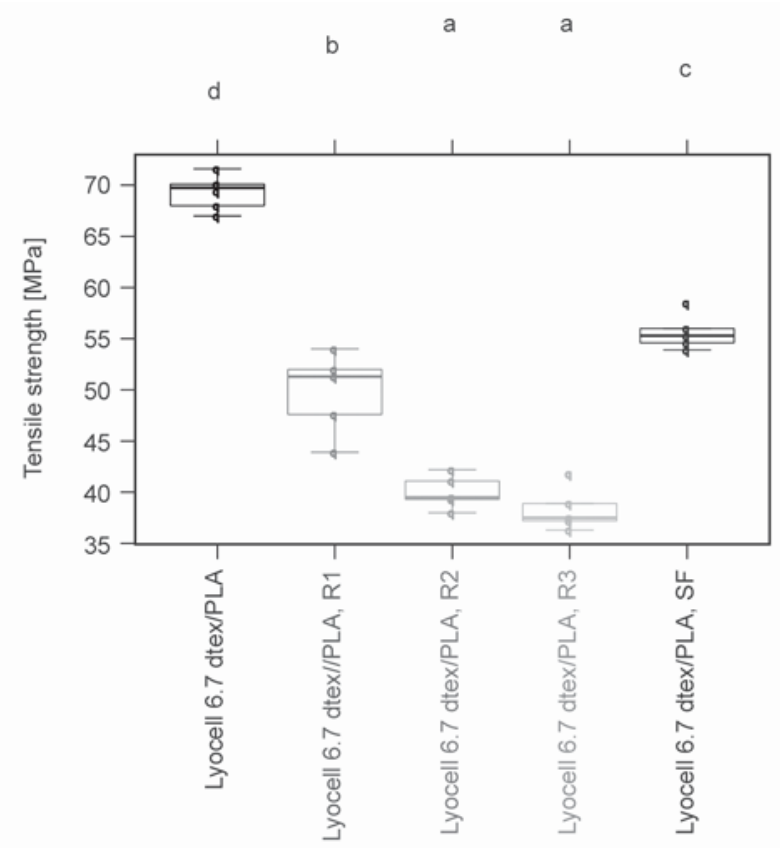

Figure 11. Tensile strength of lyocell $6.7 \mathrm{dtex} / \mathrm{PLA}$ in virgin state, reprocessed and reinforced with short fibres (SF) shown as Box-Whisker plots (significant differences are marked with different letters; all results are distributed normally) ditionally, the tensile strength of SF-reinforced composites is presented. A drastic decrease in tensile strength by a factor of 0.72 when compared to the virgin composite with a value of $70( \pm 1.2) \mathrm{MPa}$ is visible for the once recycled $(\mathrm{R} 1)$ composite $(51( \pm 3.2) \mathrm{MPa})$. The second reprocessing step leads to a further decrease in tensile strength to a value of $40( \pm 1.3) \mathrm{MPa}$, compared to the first reprocessing step this is a factor of 0.78 . The third step only results in a slight decrease by a factor of $0.95(38( \pm 1.6) \mathrm{MPa})$ compared to the second reprocessing cycle.

As presented in Figure 9 and 10, the fibre lengths show a similar distribution for R3 composites and virgin SF composites. Despite a slightly lower fibre length of SF composites compared to R1 composites a significantly higher reinforcement effect was determined resulting in a tensile strength of $55( \pm 1.3) \mathrm{MPa}$. From these findings we conclude that the strength of reprocessed composites is not only reduced by fibre shortening but may also be a result of fibre damage and a possible degradation of the PLA matrix due to residual moisture. Residual moisture is higher in cellulose fibre-reinforced composites compared to the neat matrix leading to a decreasing molecular weight and lower strength of PLA. Multiple drying steps and reprocessing may lead to further hydrolysis of polymer chains [31], and thus a lower strength compared to the SF-reinforced composite.

\subsubsection{Thermal behaviour}

The DSC scan in Figure 12 shows the heat flow as a function of temperature for the first and second heating cycle of a virgin lyocell SF-reinforced $6.7 \mathrm{dtex} /$ PLA and a threefold (R3) recycled lyocell $6.7 \mathrm{dtex} /$ PLA composite with a similar fibre length distribution. The curve progression is comparable to neat PLA $[39,40]$. Not any significant differences were found between the virgin and the recycled composites. The first heating shows a clear glass transition 

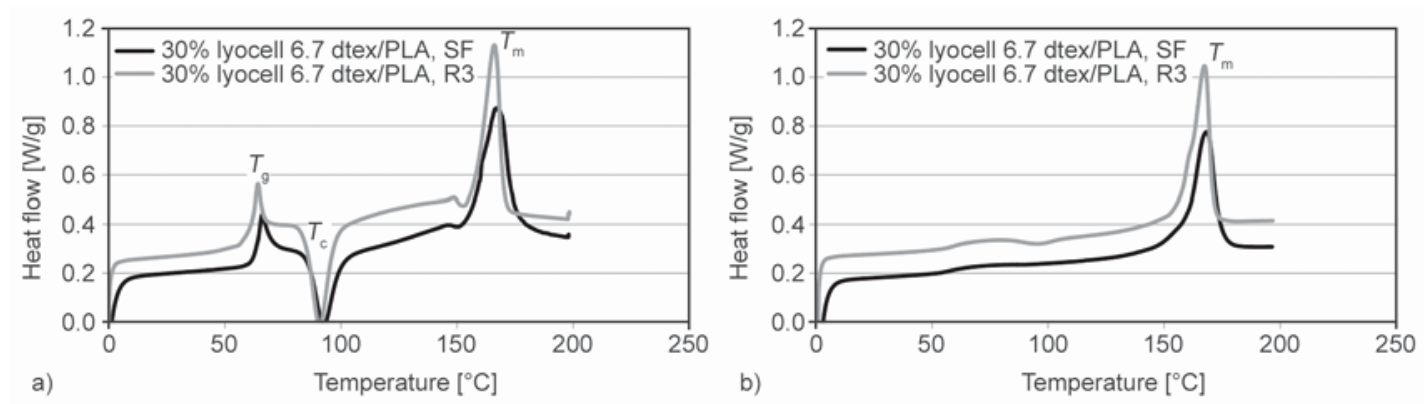

Figure 12. DSC scan of the first heating cycle (a) (first peak: glass transition temperature $T_{\mathrm{g}}$, second peak: cold crystallisation temperature $T_{\mathrm{c}}$, third peak: melting temperature $T_{\mathrm{m}}$ ) and the second heating cycle (b) of virgin SF lyocell 6.7 dtex/PLA composites and threefold recycled lyocell 6.7 dtex/PLA

and crystallisation temperature peak while this information is lost after the second heating due to crystallisation of the PLA matrix. The glass transition temperature $T_{\mathrm{g}}$ of the first heating, was determined to be at $60.3{ }^{\circ} \mathrm{C}$ for both samples. The cold crystallisation temperature $T_{\mathrm{c}}$ was only slightly lower for the recycled composite with $90.5^{\circ} \mathrm{C}$ compared to the virgin composites with $91.6^{\circ} \mathrm{C}$. Moreover, the melting temperature $T_{\mathrm{m}}$ was determined to be $167^{\circ} \mathrm{C}$ for the virgin sample which shifted slightly to $166^{\circ} \mathrm{C}$ for the recycled composite. The second heating resulted in a similar melting temperature which was determined to be $168^{\circ} \mathrm{C}$ for the virgin sample and $167^{\circ} \mathrm{C}$ for the reprocessed sample. Thus it can be concluded that the thermal behaviour of cellulose fibre-reinforced PLA does not significantly change due to reprocessing.

\subsubsection{Fracture behaviour and fibre damage}

SEM micrographs of fracture surfaces of virgin lyocell 6.7 dtex/PLA, lyocell 6.7 dtex SF/PLA and reprocessed (R1, R2 and R3) lyocell 6.7 dtex/PLA indicate a trend of higher fibre pull-out with an increasing number of reprocessing cycles (compare Figure 13). When comparing virgin composites with virgin SF-reinforced composites, one can see that fibres of the virgin composites show a higher pull-out length. This phenomenon occurs due to the longer fibres since the production procedures were exactly the same. Usually fibre debonding starts at the fibre ends and the shorter the fibre, the easier the fibre is pulled out of the matrix [35]. The gaps between fibre and matrix however appear to be in a similar range which indicates a similar fibre/matrix adhesion. Gaps or voids respectively, would lead to a clear decrease of the fibre/matrix adhesion.

Aside from fibre shortening, the fibres are clearly damaged as a result of reprocessing. SEM investigations of at least 50 reprocessed fibres were carried out. For example the appearance of SF fibres extracted from a virgin composite and fibres from a reprocessed composite (R3) are shown in Figure 14. Figure 14a and $14 \mathrm{~b}$ indicate a smooth surface and display the low damage to SF. Threefold reprocessed fibres show the beginning of fibre fibrillation (Figure 14c) and strong fibre damage (Figure 14d) which may result in reduced fibre tensile strength.

\subsection{Recycling behaviour of man-made cellulose fibre-reinforced PLA compared to other composites}

It is well known that the mechanical performance of fibre-reinforced plastics depends on the nature and intrinsic properties of the polymer matrix, surface characteristics, strength, shape and orientation of fibres, the interfacial quality between fibre and matrix as well as the processing stages and applied parameters, etc.. Clearly the fibre length may be affected by the production process. Usually the reprocessing or recycling of fibre-reinforced plastics leads to a clear reduction in the fibre length. However, the aspect ratio is not necessarily reduced. Unlike regenerated or man-made fibres, natural fibres can exist as individual fibres or fibre bundles. An advantage of natural fibre bundles is that they may be split into smaller fibre bundles or single fibres, reducing the global cross-section leading to a higher aspect ratio despite length reduction [9]. Therefore, a recycling of composites reinforced with natural fibre bundles often only has a negative influence on the composite strength after several recycling steps. This phenomenon was observed by different authors for different natural fibre bundles in variable matrices, eg. for flax/PLA [9], flax/PP [4, 8], hemp/PP [2, 3], sisal/PP [2, 3], wood fibre/PP [4] or alfa fibre/PVC [12]. Nevertheless, the 

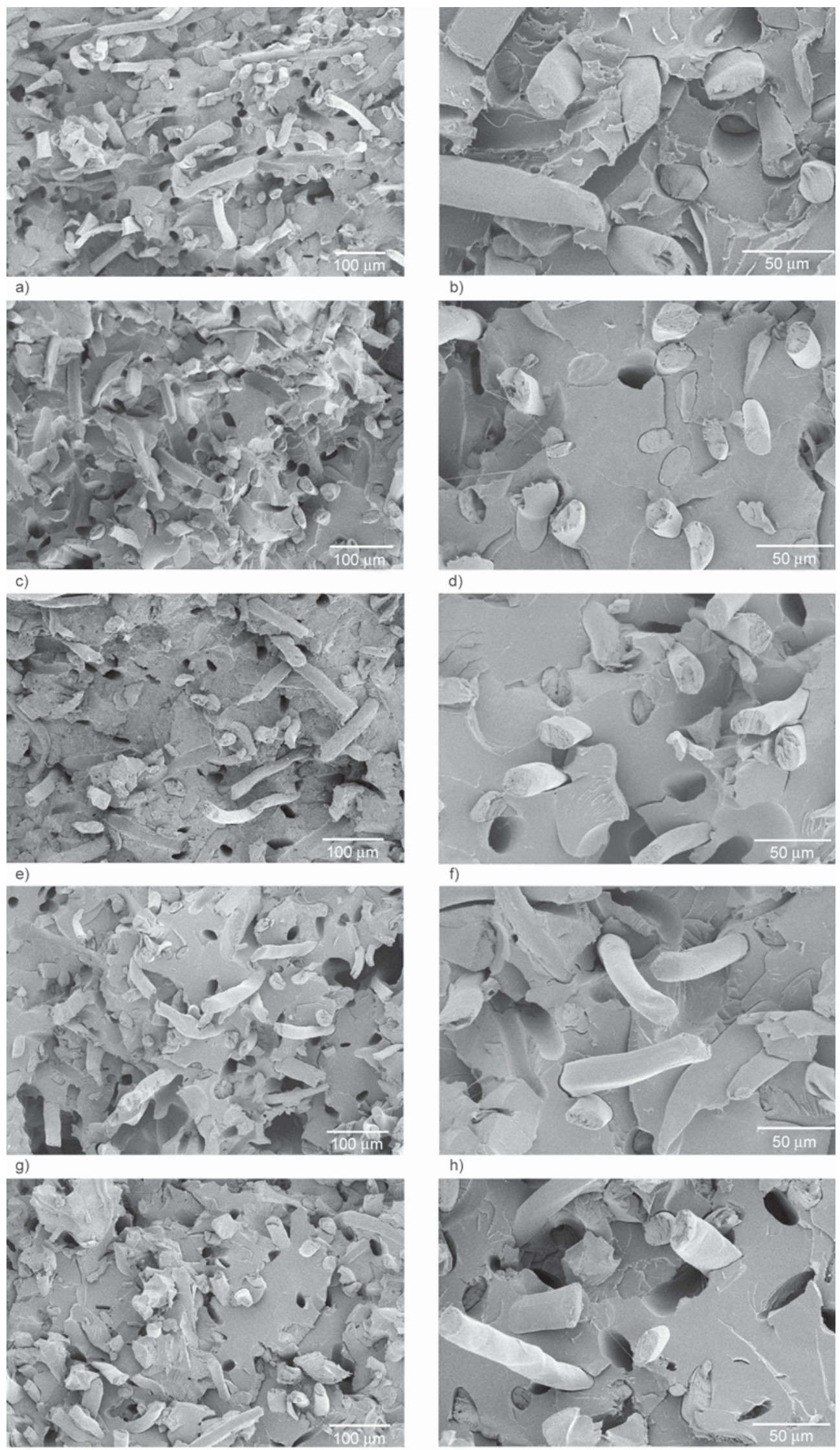

i)

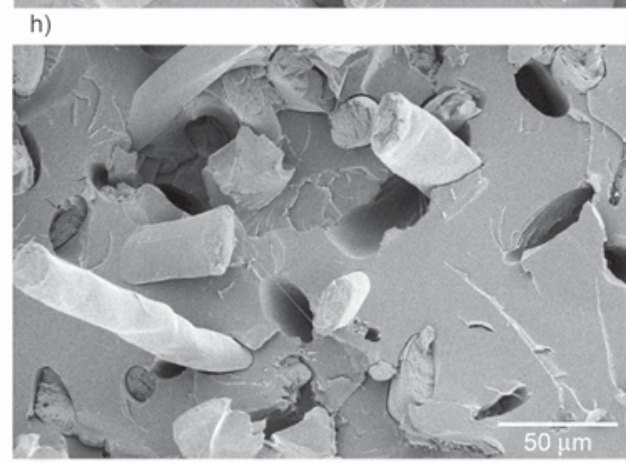

j)

Figure 13. SEM micrographs of virgin lyocell/PLA (a and b), virgin lyocell SF/PLA (c and d), reprocessed R1 (e and f), reprocessed R2 (g and $h$ ) and reprocessed R3 lyocell/PLA ( $i$ and $j$ ). 


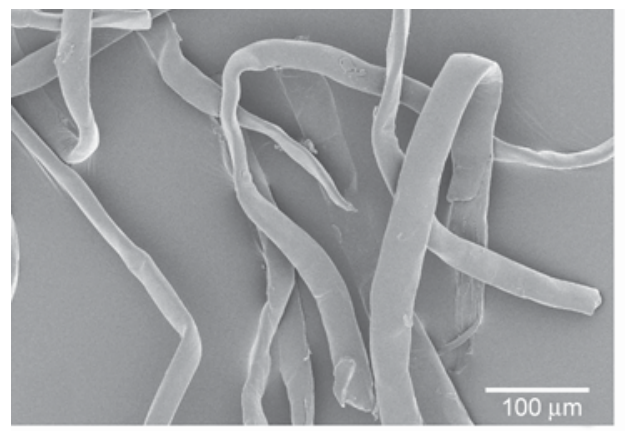

a)

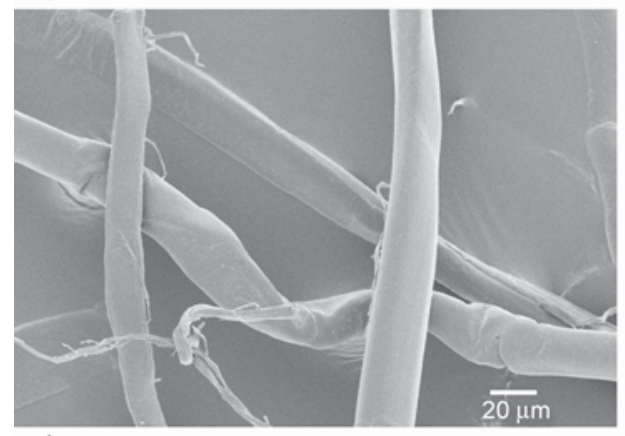

c)

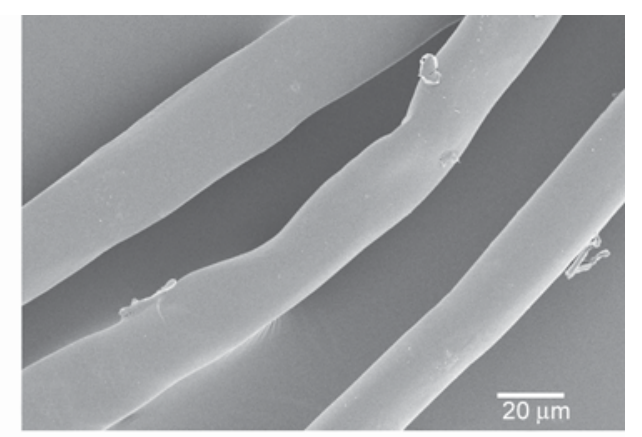

b)

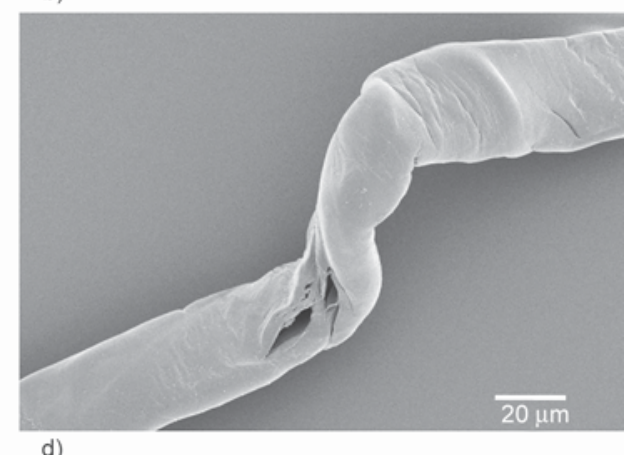

d)

Figure 14. SEM micrographs of fibres extracted from virgin SF lyocell/PLA composites (a and b) and reprocessed (R3) lyocell/PLA composites (c and d)

fibre bundle may be damaged with an increasing number of recycling steps, especially if the fibre bundles are already split into single fibres, leading to lower mechanical composite characteristics as a consequence of reprocessing $[2,3]$.

In contrast to this man-made single fibres, such as glass fibres, break if a critical stress is reached. This breakage reduces the fibre length which leads to a reduced aspect ratio and a reduction in tensile strength of the composites [4]. During the recycling of lyocell, fibre breakage also leads to a decreased aspect ratio and thus, among other aspects such as degradation of matrix and fibre damage, to a significant reduction of the composite strength. Regarding the recycling behaviour, natural fibre bundles therefore display the greater potential compared to regenerated cellulose fibres.

\section{Conclusions}

Similarly to other single fibres, the aspect ratio of lyocell fibres decreases clearly as a result of reprocessing. A DSC analysis of virgin composites and three times reprocessed composites with a similar fibre length distribution resulted in similar thermal behaviour regarding glass transition, crystallisation and melting temperature.
The tensile and impact strength of pure PLA was only slightly affected by reprocessing. It is concluded that pure PLA was not significantly damaged due to reprocessing, however the mechanical characteristics of the composites are significantly reduced by the first reprocessing step. It can be shown that the decrease in fibre length was higher for finer fibres when compared to coarser fibres. Finer fibres however display a higher aspect ratio leading to a higher reinforcing potential. All results of tensile strength fit well with the determined fibre length and aspect ratio values. While fibres with a median fibre length higher than the critical fibre length lead to a reinforcing effect in the composite, a fibre length at the level of the critical fibre length leads to tensile strength values with the level of a pure matrix. A fibre length smaller than the critical fibre length resulted in a lower tensile strength when compared to neat PLA. Besides fibre shortening, the degradation and damage of the fibres and the matrix as a result of hydrolysis due to the higher moisture level of cellulose fibres during reprocessing has a negative impact on the tensile strength of the composites. This aspect should be addressed in further research activities. Regarding the recycling potential, natural fibre bundles should be prefererred to single cellulose fibres due to the advantage of being able 
to split them into finer bundles or single fibres leading to a lower decrease of the composite strength.

\section{Acknowledgements}

The authors acknowledge Petra Droettbroom (Institute for polymer materials and plastics processing, TU Clausthal, Germany) for DSC analyses and Birgit Uhrlaub (The Biological Materials Group, HSB - Hochschule Bremen, City University of Applied Sciences, Germany) for SEM investigations. The authors would also like to acknowledge the reviewers who helped to improve this manuscript and Peter Weir for proof reading.

\section{References}

[1] Oliveux G., Dandy L. O., Leeke G. A.: Current status of recycling of fibre reinforced polymers: Review of technologies, reuse and resulting properties. Progress in Materials Science, 72, 61-99 (2015).

DOI: $10.1016 /$ j.pmatsci.2015.01.004

[2] Bourmaud A., Baley C.: Investigations on the recycling of hemp and sisal fibre reinforced polypropylene composites. Polymer Degradation and Stability, 92, 1034 1045 (2007). DOI: $10.1016 /$ j.polymdegradstab.2007.02.018

[3] Bourmaud A., Baley C.: Rigidity analysis of polypropylene/vegetal fibre composites after recycling. Polymer Degradation and Stability, 94, 297-305 (2009).

DOI: $10.1016 /$ j.polymdegradstab.2008.12.010

[4] Dickson A. R., Even D., Warnes J. M., Fernyhough A.: The effect of reprocessing on the mechanical properties of polypropylene reinforced with wood pulp, flax or glass fibre. Composites Part A: Applied Science and Manufacturing, 61, 258-267 (2014).

DOI: 10.1016/j.compositesa.2014.03.010

[5] Bernasconi A., Rossin D., Armanni C.: Analysis of the effect of mechanical recycling upon tensile strength of a short glass fibre reinforced polyamide 6,6. Engineering Fracture Mechanics, 74, 627-641 (2007).

DOI: $10.1016 /$ j.engfracmech.2006.10.002

[6] Barth M., Carus M.: Carbon footprint and sustainability of different natural fibre for biocomposites and insulation material. Study providing data for the automotive and insulation industry. Nova Institute, Hürth, Germany (2015).

[7] Directive 2000/53/ec of the European parliament and of the council of 18 September 2000 - on end-of life vehicles. Official Journal of the European Communities, p.15 (2000).

[8] Arbelaiz A., Fernández B., Ramos J., Retegi A., LlanoPonte R., Mondragon I.: Mechanical properties of short flax fibre bundle/polypropylene composites: Influence of matrix/fibre modification, fibre content, water uptake and recycling. Composites Science and Technology, 65, 1582-1592 (2005).

DOI: $10.1016 /$ j.compscitech.2005.01.008
[9] Le Duigou A., Pillin I., Bourmaud A., Davies P., Baley C.: Effect of recycling on mechanical behaviour of biocompostable flax/poly(L-lactide) composites. Composites Part A: Applied Science and Manufacturing, 39, 1471-1478 (2008).

DOI: $10.1016 /$ j.compositesa.2008.05.008

[10] Beg M., Pickering K.: Reprocessing of wood fibre reinforced polypropylene composites. Part I: Effects on physical and mechanical properties. Composites Part A: Applied Science and Manufacturing, 39, 1091-1100 (2008).

DOI: $10.1016 /$ j.compositesa.2008.04.013

[11] Fonseca-Valero C., Ochoa-Mendoza A., Arranz-Andrés J., González-Sánchez C.: Mechanical recycling and composition effects on the properties and structure of hardwood cellulose-reinforced high density polyethylene eco-composites. Composites Part A: Applied Science and Manufacturing, 69, 94-104 (2015).

DOI: $10.1016 /$ j.compositesa.2014.11.009

[12] Hammiche D., Bourmaud A., Boukerrou A., Djidjelli H., Grohens Y.: Number of processing cycle effect on the properties of the composites based on alfa fiber. Journal of Thermoplastic Composite Materials, in press, (2016).

DOI: $10.1177 / 0892705714563116$

[13] Joffre T., Miettinen A., Wernersson E. L., Isaksson P., Gamstedt E. K.: Effects of defects on the tensile strength of short-fibre composite materials. Mechanics of Materials, 75, 125-134 (2014).

DOI: $10.1016 /$ j.mechmat.2014.04.003

[14] Beaugrand J., Berzin F.: Lignocellulosic fiber reinforced composites: Influence of compounding conditions on defibrization and mechanical properties. Journal of Applied Polymer Science, 128, 1227-1238 (2013). DOI: $10.1002 /$ app. 38468

[15] Le Moigne N., van den Oever M., Budtova T.: A statistical analysis of fibre size and shape distribution after compounding in composites reinforced by natural fibres. Composites Part A: Applied Science and Manufacturing, 42, 1542-1550 (2011).

DOI: 10.1016/j.compositesa.2011.07.012

[16] Graupner N., Müssig J.: A comparative study on cellulose fibre-reinforced PLA and PP composites: Compression moulding vs. injection moulding. in 'ICNF 2015 - From Nature to Market: $2^{\text {nd }}$ International Conference on Natural Fibres. Ponta Delgada, Portugal (2015).

[17] Fu S-Y., Lauke B.: Effects of fiber length and fiber orientation distributions on the tensile strength of shortfiber-reinforced polymers. Composites Science and Technology, 56, 1179-1190 (1996). DOI: $10.1016 / \mathrm{S} 0266-3538(96) 00072-3$

[18] Thomson C., Lowe R., Ragauskas A.: Imaging cellulose fibre interfaces with fluorescence microscopy and resonance energy transfer. Carbohydrate Polymers, 69, 799-804 (2007). DOI: $10.1016 /$ j.carbpol.2007.01.023 
[19] DIN EN ISO 527-2: Plastics - Determination of tensile properties - Part 2: Test conditions for moulding and extrusion plastics (1996).

[20] DIN EN ISO 291: Plastics - Standard atmospheres for conditioning and testing (2006).

[21] DIN EN ISO 179: Plastics - Determination of Charpy impact properties - Part 1: Non-instrumented impact test (1997).

[22] DIN EN ISO 139: Textiles - Standard atmospheres for conditioning and testing (2005).

[23] Graupner N., Rößler J., Ziegmann G., Müssig J.: Fibre/ matrix adhesion of cellulose fibres in PLA, PP and MAPP: A critical review of pull-out test, microbond test and single fibre fragmentation test results. Composites Part A: Applied Science and Manufacturing, 63, 133 148 (2014).

DOI: $10.1016 /$ j.compositesa.2014.04.011

[24] Shapiro S. S., Wilk M. B.: An analysis of variance test for normality (complete samples). Biometrika, 52, 591611 (1965).

DOI: 10.1093/biomet/52.3-4.591

[25] Tukey J. W.: Comparing individual means in the analysis of variance. Biometrics, 5, 99-114 (1949).

[26] Wilcoxon F.: Individual comparisons by ranking methods. Biometrics Bulletin, 1, 80-83 (1945).

[27] Sachs L.: Angewandte Statistik Anwendung statistischer Methoden (in German). Springer, Berlin (1984).

[28] Frigge M., Hoaglin D. C., Iglewicz B.: Some implementations of the boxplot. The American Statistician, 43, 50-54 (1989).

[29] Moon C. K., Lee J-O., Cho H. H., Kim K. S.: Effect of diameter and surface treatment of fiber on interfacial shear strength in glass fiber/epoxy and HDPE. Journal of Applied Polymer Science, 45, 443-450 (1992). DOI: $10.1002 / a p p .1992 .070450309$

[30] Wilson D. M.: Statistical tensile strength of Nextel ${ }^{\mathrm{TM}}$ 610 and Nextel ${ }^{\text {TM }} 720$ fibres. Journal of Materials Science, 32, 2535-2542 (1997).

DOI: 10.1023/A:1018538030985

[31] Courgneau C., Rusu D., Henneuse C., Ducruet V., Lacrampe M-F., Krawczak P.: Characterisation of lowodour emissive polylactide/cellulose fibre biocomposites for car interior. Express Polymer Letters, 7, 787 804 (2013).

DOI: 10.3144/expresspolymlett.2013.76
[32] Lekube B.: The influence of bioplastics on the recycling of conventional plastics. in ' $23^{\text {rd }}$ annual meeting of the Bio-Environmental Polymer Society (BEPS), Karlsruhe, Germany' (2015).

[33] Graupner N.: Analyse und Optimierung der Strukturund Eigenschaftsbeziehungen von cellulosefaserverstärkten Polylactid-Verbundwerkstoffen (in German). Papierflieger Verlag, Clausthal-Zellerfeld (2014).

[34] Erdmann J., Ganster J.: Einfluss des Faserdurchmessers auf die Struktur und Mechanik Cellulosefaser-verstärkter PLA-Komposite (in German). Lenzinger Berichte, 89, 91-102 (2011).

[35] Graupner N., Ziegmann G., Wilde F., Beckmann F., Müssig J.: Procedural influences on compression and injection moulded cellulose fibre-reinforced polylactide (PLA) composites: Influence of fibre loading, fibre length, fibre orientation and voids. Composites Part A: Applied Science and Manufacturing, 81, 158-171 (2016).

DOI: 10.1016/j.compositesa.2015.10.040

[36] Piggott M. R.: Why interface testing by single-fibre methods can be misleading. Composites Science and Technology, 57, 965-974 (1997). DOI: $10.1016 / \mathrm{S} 0266-3538(97) 00036-5$

[37] Zhang H., Ericson M. L., Varna J., Berglund L. A.: Transverse single-fibre test for interfacial debonding in composites: 1. Experimental observations. Composites Part A: Applied Science and Manufacturing, 28, 309-315 (1997). DOI: $10.1016 / \mathrm{S} 1359-835 \mathrm{X}(96) 00123-6$

[38] ISO 22314: Plastics. Glass-fibre-reinforced products. Determination of fibre length (2006).

[39] Gregorova A.: Application of differential scanning calorimetry to the characterization of biopolymers. in 'Applications of calorimetry in a wide context - Differential scanning calorimetry, isothermal titration calorimetry and microcalorimetry' (eds.: Elkordy A. A.) InTech, Rijeka, p.18 (2013). DOI: $10.5772 / 53822$

[40] Chun K. S., Husseinsyah S.: Polylactic acid/corn cob eco-composites. Effect of new organic coupling agent. Journal of Thermoplastic Composite Materials, 27, 1667-1678 (2014). DOI: $10.1177 / 0892705712475008$ 